\title{
Simulation and evaluation of 2-m temperature over Antarctica in polar regional climate model
}

\author{
XIN YuFei ${ }^{1}$, BIAN LinGen $^{1 *}$, Annette RINKE ${ }^{2} \&$ Klaus DETHLOFF ${ }^{2}$ \\ ${ }^{1}$ Chinese Academy of Meteorological Science, Beijing 100081, China; \\ ${ }^{2}$ Alfred Wegener Institute for Polar and Marine Research, Bremerhaven 27570, Germany
}

Received March 13, 2013; accepted May 15, 2013

\begin{abstract}
The European Centre for Medium-Range Weather Forecasts Reanalysis ERA40, National Centers for Environmental Prediction (NCEP) 20th-century reanalysis, and three station observations along an Antarctic traverse from Zhongshan to Dome-A stations are used to assess 2-m temperature simulation skill of a regional climate model. This model (HIRHAM) is from the Alfred Wegener Institute for Polar and Marine Research in Germany. Results show: (1) The simulated multiyear averaged 2-m temperature field pattern is close to that of ERA40 and NCEP; (2) the cold bias relative to ERA40 over all of Antarctic regions is $1.8^{\circ} \mathrm{C}$, and that to NCEP reaches $5.1^{\circ} \mathrm{C}$; (3) bias of HIRHAM relative to ERA40 has seasonal variation, with a cold bias mainly in the summer, as much as $3.4^{\circ} \mathrm{C}$. There is a small inland warm bias in autumn of $0.3^{\circ} \mathrm{C}$. Further analysis reveals that the reason for the cold bias of 2-m temperature is that physical conditions of the near-surface boundary layer simulated by HIRHAM are different from observations: (1) During the summer, observations show that near-surface atmospheric stability conditions have both inversions and non-inversions, which is due to the existence of both positive and negative sensible heat fluxes, but HIRHAM almost always simulates a situation of inversion and negative sensible heat flux; (2) during autumn and winter, observed near-surface stability is almost always that of inversions, consistent with HIRHAM simulations. This partially explains the small bias during autumn and winter.
\end{abstract}

polar regional climate model, 2-m temperature, air temperature inversion, sensible heat flux

Citation: Xin Y F, Bian L G, Rinke A, et al. Simulation and evaluation of 2-m temperature over Antarctica in polar regional climate model. Science China: Earth Sciences, 2013, doi: 10.1007/s11430-013-4709-z

The area of the Antarctic region (south of $60^{\circ} \mathrm{S}$, including Antarctica and high-latitude Southern Ocean) is 52 million $\mathrm{km}^{2}$. Antarctica makes up 14 million $\mathrm{km}^{2}$, which includes three parts: East Antarctica, West Antarctica, and the Antarctic Peninsula. The region is important in the global climate system. First is its cold climate; the inland plateau average annual temperature is about $-56^{\circ} \mathrm{C}$, and the region is one of the earth's primary cold sources and an important driving force of global atmospheric zonal circulation (Allison et al., 1983). Second is the albedo of Antarctic ice sheets, ice shelves and Southern Ocean sea ice. A change of

*Corresponding author (email: blg@cams.cma.gov.cn)
Antarctic albedo will have a significant impact on the global climate system (Qu et al., 2005). Finally, the Antarctic ice sheet consolidates $90 \%$ of global freshwater, and its change would have tremendous impact on global sea level and ocean circulation (Wild et al., 2003).

Global circulation models (GCMs) represent powerful tools for study of the climate system and climate change. However, they have shortcomings in investigating local climate systems and climate change, because their spatial resolution is limited by computer capabilities (Meehl et al., 2007). Dynamical downscaling makes up for this deficiency (Giorgi et al., 1991). Using GCM outputs as initial and boundary conditions and assimilating observations, it drives limited area models (LAMs) whose dynamic framework 
and physical processes are superior to those of GCMs, and whose resolutions are also finer. Studies have shown that LAMs can significantly improve simulation resolution, and the simulation results are closer to observations (Gao et al., 2006, 2011). In recent years, some LAMs have been applied to the Antarctic region (Glushak, 2008; Bailey et al., 2000a, 2000b; Powers et al., 2003), but they were unsatisfactory because of the unique nature of the underlying surface and physical atmospheric processes (ice cloud and others), as well as terrain complexity. Fraedrich et al. (1991) pointed out that because of the strongly baroclinic atmosphere of the Antarctic, LAM prediction error grows rapidly, at a rate twice that in mid latitudes. Bromwich et al. (2005) assessed the Antarctic Mesoscale Prediction System (AMPS), which was jointly developed by the US National Center for Atmospheric Research (NCAR) and Ohio State University (OSU). They found that although the model can forecast trends of upper-air temperature and wind, they had phase lags with observations and simulation of ground temperature and low-layer wind was poor. Connolley et al. (1994) used observational data to test the UK Meteorological Office Antarctic regional climate mode (UM), and the results showed inland air temperature was underestimated. Reijmer et al. (2005) evaluated a Royal Netherlands Meteorological Institute Antarctic regional climate model (RACMO2/ANT) using 1-year observation data, finding that January bias relative to ERA40 simulation reached $-4^{\circ} \mathrm{C}$, although annual mean bias was small. Xin et al. (2010) tested the German Alfred Wegener Institute (AWI) for Polar and Marine Research regional climate model HIRHAM, using radiosonde observations from Australian sites Davis, Mawson and Casey in the Antarctic. The results showed that temperature in the free layer was simulated well, but not so in the boundary layer.

Assessments of Antarctic LAMs have been limited by observations, because of an uneven distribution of the observational network, missing data in polar winter, and short time series. Mesoscale weather processes have been evaluated by numerous researchers, but there has been less evaluation of regional climate models of the Antarctic (Christensen et al., 2007). Air temperature at 2-m height is an essential element of Antarctic meteorological observation; it is an important link with snow-layer temperature and an important factor in surface energy balance estimates (Chen et al., 2010a, 2010b). In this work, data along the Antarctic traverse from Chinese Zhongshan to Dome-A stations, other Antarctic station data, plus ERA40 and NCEP 20th century reanalyses are used to assess 2-m temperature simulated by HIRHAM. Major causes of bias are determined, which will aid HIRHAM development and improve its simulation skill.

\section{Model, data and method}

\subsection{Introduction of model}

HIRHAM (Christensen et al., 2006) is an atmospheric regional climate model (RCM) based on a subset of the High Resolution Limited Area Model (HIRLAM) (Undén et al., 2002) and ECHAM models (Roeckner et al., 2003), combining the dynamics of the former with physical parameterization schemes of the latter. The HIRLAM is a numerical short-range weather forecasting system developed by the international HIRLAM program, and is used for routine weather forecasting at several meteorological institutes. The ECHAM GCM is a general atmospheric circulation model developed at the Max Planck Institute (MPI) for Meteorology, in collaboration with external partners. The original HIRHAM model was from collaboration between the Denmark Meteorological Institute, Royal Netherlands Meteorological Institute (KNMI), and MPI. The latest operational version of the HIRHAM modeling system, version 5, added polar physical parameterizations and was applied in the Arctic and Antarctic. HIRHAM has static vertical equilibrium and a horizontally uniform grid. Its horizontal resolution is $0.5^{\circ} \times 0.5^{\circ}$, or about $50 \mathrm{~km}$. The time differential scheme uses a semi-implicit, semi-Lagrangian scheme. The main physical parameters of the program are shown in Table 1 .

\subsection{Data and methods}

The data used included the following: HIRHAM output (Glushak, 2008), including monthly mean data and fourtimes-daily data. The monthly mean data are from 1958 to 1998 (a total of 41 years), and daily data are from 2005 to 2008 (a total of 4 years). Resolutions are all about $50 \mathrm{~km}$.

Monthly means from ERA40 reanalysis between 1958 and 1998 , with resolution about $2.5^{\circ} \times 2.5^{\circ}$. Monthly means from NCEP 20th-century reanalysis between 1958 and 1998, with resolution about $1.9^{\circ} \times 1.9^{\circ}$.

Antarctic station observations, including: (1) Automatic Weather Station (AWS) data along the traverse from Zhongshan to Dome-A. The traverse and Antarctic topographic map are shown in Figure 1. The three AWSs are Zhongshan $\left(68.6^{\circ} \mathrm{S}, 78.0^{\circ} \mathrm{E}\right.$; altitude $\left.0 \mathrm{~m}\right)$, Eagle $\left(76.4^{\circ} \mathrm{S}, 77.0^{\circ} \mathrm{E}\right.$; altitude $2852 \mathrm{~m})$ and Dome-A $\left(80.4^{\circ} \mathrm{S}, 77.4^{\circ} \mathrm{E}\right.$; altitude $\left.4093 \mathrm{~m}\right)$. Observation data from these sites are daily, from 2005 to 2008. Observed elements are air temperature, wind speed, and wind direction at three levels (1, 2 and $4 \mathrm{~m}$ ). Data were strictly quality-controlled (Ma, 2009). (2) Ultrasonic data, for turbulent sensible heat and momentum fluxes

Table 1 Major physical parameterization schemes of HIRHAM model

\begin{tabular}{ccc}
\hline Radiation scheme & Cumulus convection scheme & Boundary layer scheme \\
\hline University of Lille Scheme (Fouquart et al., 1980) & Tiedtke Scheme (Tiedtke, 1989) & Based on local $K$ theory \\
\hline
\end{tabular}




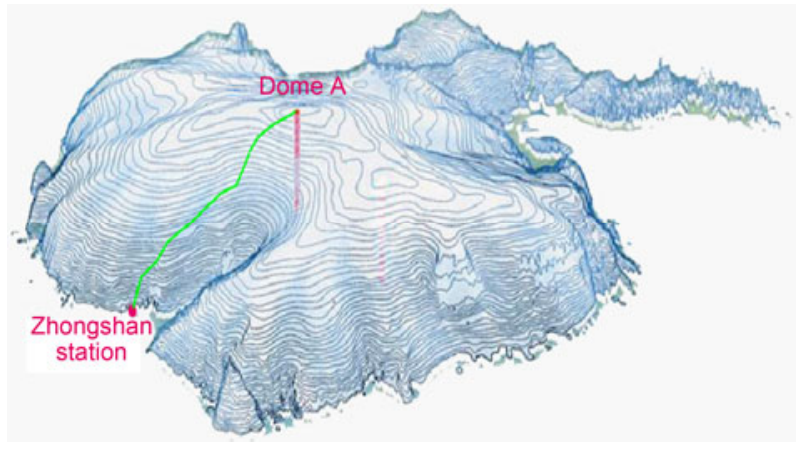

Figure 1 Antarctic traverse from Chinese Zhongshan to Dome-A stations and Antarctic topographic map.

derived for Zhongshan station in 2008. Raw data quality control included deletion of abnormal values, noise removal via standard deviation, and use of the triple coordinate rotation method (Ma, 2009). (3) Monthly mean 2-m air temperature time series at two stations, namely Amundsen Scott $\left(90^{\circ} \mathrm{S}, 0^{\circ} \mathrm{E}\right.$; altitude $\left.2835 \mathrm{~m}\right)$ and Halley $\left(75.5^{\circ} \mathrm{S}, 26.4^{\circ} \mathrm{W}\right.$; altitude $30 \mathrm{~m}$ ), from 1979 to 1998 .

\section{Results}

\subsection{2-m air temperature}

Figure 2 shows a multiyear averaged 2-m temperature field over the Antarctic region, simulated by HIRHAM. From Figures 1 and 2, one sees that as altitude increases,

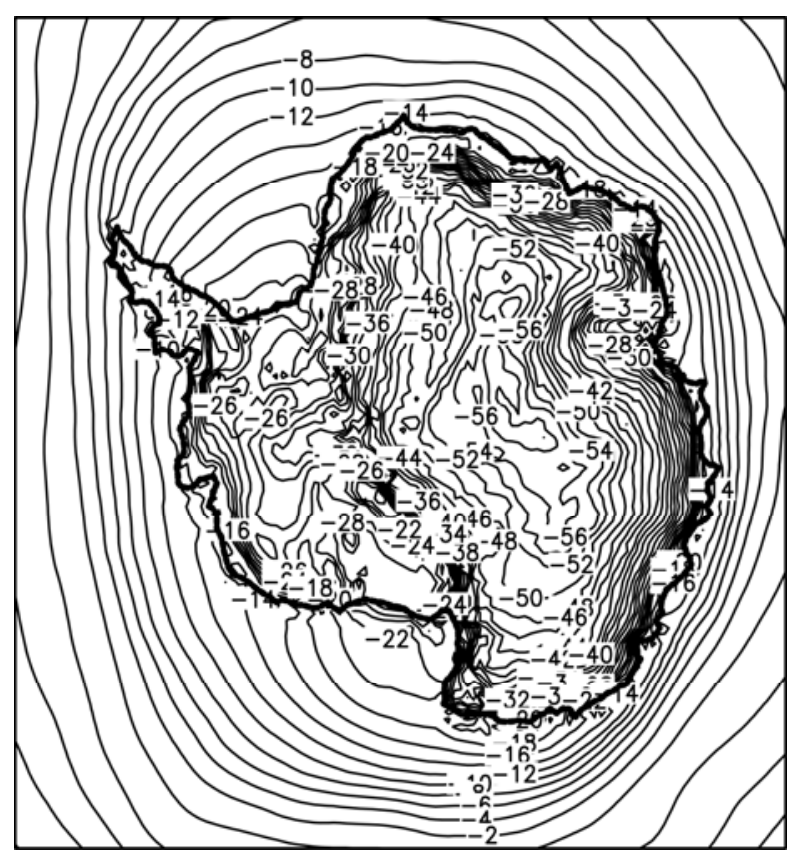

Figure 2 Multiyear mean (1958-1998) 2-m temperature field in Antarctica (area south of $60^{\circ} \mathrm{S}$ ) of HIRHAM. Domain horizontal grid is rotated latitude/longitude grid with $110 \times 122$ points, centered on South Pole. temperature gradually decreases, and isotherms approximately parallel contour lines. Temperature gradient maxima often appear at the maximum slope of the East Antarctic and West Antarctic ice sheets. The center of Antarctic cold air remains near Dome-A, with temperature below $-58^{\circ} \mathrm{C}$. The 2-m temperature field is similar to ERA40 (Figure 3(a)), including the cold air center and gradient maximum area. However, there is inland cold bias relative to ERA40 (Figure 3(b)). There is a large bias area in East Antarctica, colder than ERA 40 by $4^{\circ} \mathrm{C}$. The entire Antarctic region-average cold bias is $1.8^{\circ} \mathrm{C}$. Relative to the NCEP 20th-century reanalysis (Figure 3(c)), the cold bias of HIRHAM (Figure 3(d)) is larger, although the pattern is similar. Some locations have an $8^{\circ} \mathrm{C}$ cold bias, and average bias over the entire region is about $5.1^{\circ} \mathrm{C}$.

To examine the cold bias, the seasonal difference between HIRHAM and ERA40 is determined (Figure 4). There was cold bias of HIRHAM relative to NCEP in all four seasons, so their difference pattern is not shown. The figure clearly shows a cold bias during the polar day (Figure 4(a), (d)); the cold bias is not clear during the polar night (Figure 4(b), (c)). The region-average cold bias in summer (December, January, and February) is $3.4^{\circ} \mathrm{C}$, and that in spring (September, October, and November) is $2.4^{\circ} \mathrm{C}$. During autumn (March, April, and May), the cold bias disappears and the difference (HIRHAM minus ERA40) is $0.004^{\circ} \mathrm{C}$; inland it is $0.3^{\circ} \mathrm{C}$. In winter (June, July and August), the difference is $-1.3^{\circ} \mathrm{C}$ and inland only $-0.7^{\circ} \mathrm{C}$. Thus, the cold bias of the entire region originates mainly from summer.

Monthly mean 2-m air temperature time series of HIRHAM, ERA40, NCEP 20th-century reanalysis and observation at two stations are compared in Figure 5. At Amundsen Scott South Pole station from 1979 to 1998 (Figure 5(a)), it is clear that ERA40 is close to observation in winter but has a warm bias in summer. The 20-year average summer warm bias is $6.7^{\circ} \mathrm{C}$. This contrasts with NCEP, which is close in summer but has a warm bias in winter; the 20-year average winter warm bias is $10.7^{\circ} \mathrm{C}$. At Halley station (Figure 5(c)), ERA40 is close to observation, but NCEP is warmer in both winter and summer; the 20 -year average warm bias is $5.5^{\circ} \mathrm{C}$. HIRHAM is colder than observation at the two stations (Figure 5(b), (d)), $3.1^{\circ} \mathrm{C}$ at Amundsen Scott, and $3.0^{\circ} \mathrm{C}$ at Halley. This cold bias is mainly in summer (December, January, and February); the 3-month average cold bias is $9.0^{\circ} \mathrm{C}$ at Amundsen Scott and $5.2^{\circ} \mathrm{C}$ at Halley.

\subsection{Reason for 2 -m cold bias}

From the above analysis, it is clear that Antarctic 2-m air temperature simulated by HIRHAM is colder than observed, especially in summer. To find the reason for this, AWS data of the Zhongshan Station to Dome-A traverse and ultrasonic data from Zhongshan are used to analyze Antarctic boundary layer processes. The Antarctic is always covered by snow and ice, with high surface albedo, low thermodynamic 

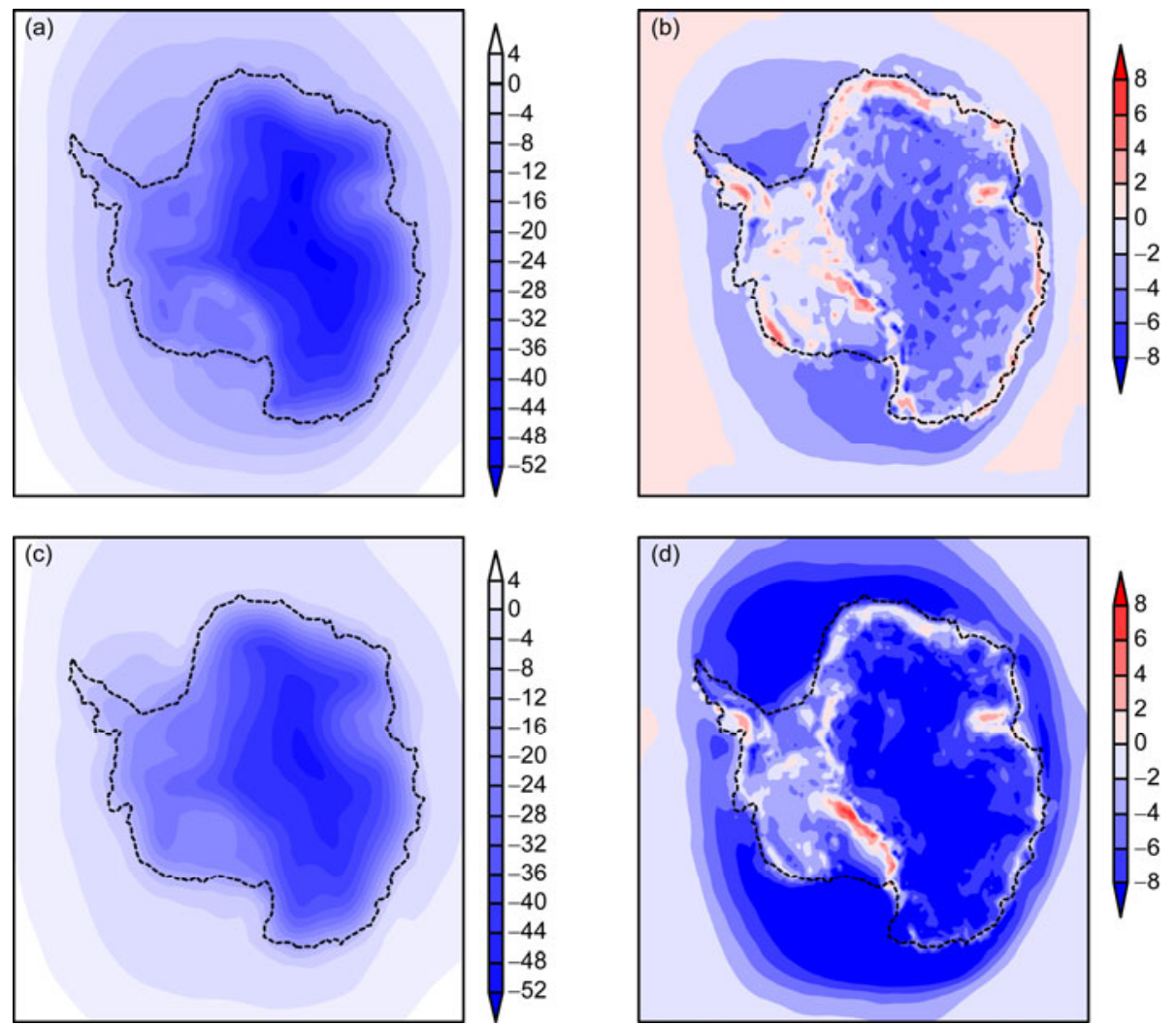

Figure 3 Multiyear mean (1958-1998) 2-m temperature field in Antarctica from reanalysis datasets. (a) ERA40; (b) HIRHAM minus ERA40; (c) NCEP 20th-century reanalysis; (d) HIRHAM minus NCEP 20th-century reanalysis.
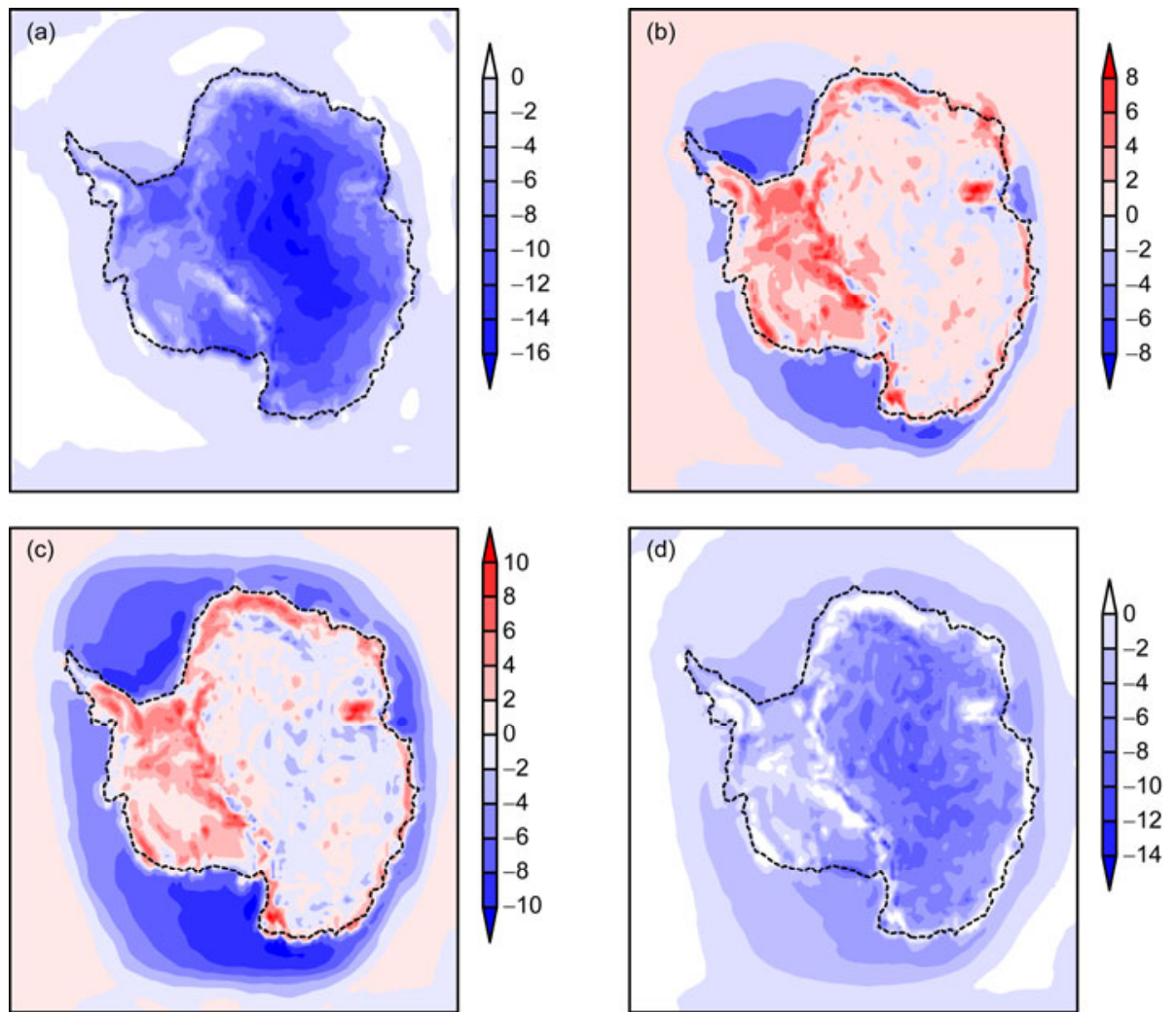

Figure 4 Multiyear mean seasonal bias of 2-m temperature field (HIRHAM minus ERA40). (a) December, January, and February; (b) March, April, and May; (c) June, July, and August; (d) September, October, and November. 


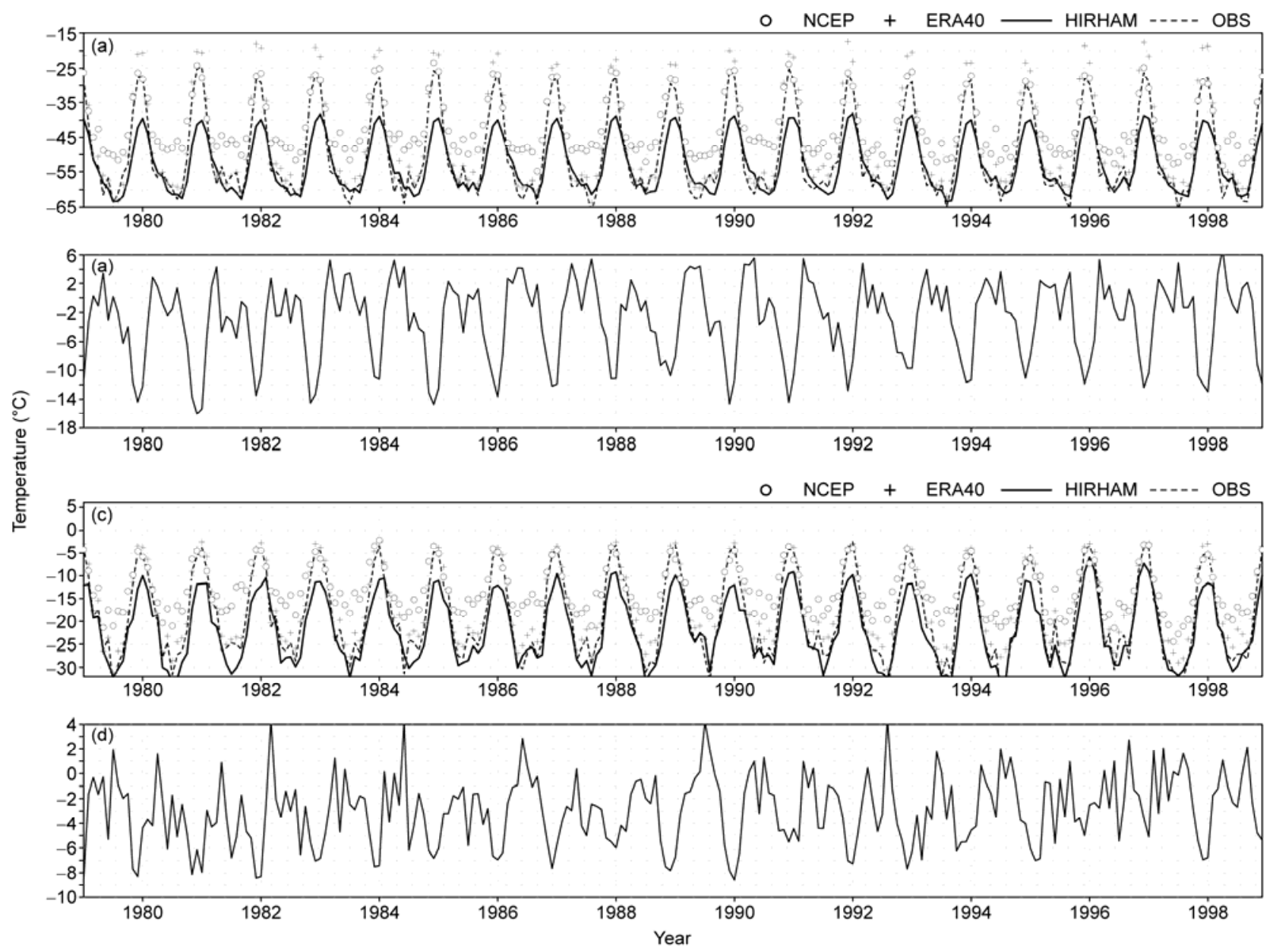

Figure 5 Monthly mean 2-m temperature contrast between site observations and HIRHAM, ERA40 and NCEP 20 th-century reanalysis, from 1979 to 1998. Observation, HIRHAM, ERA40 and NCEP 20th-century reanalysis is at (a) Amundsen Scott and (c) Halley; HIRHAM minus observation at (b) Amundsen Scott and (d) Halley.

roughness, and little solar radiation during the polar night period, resulting in negative surface net radiation most of the time. This means that the sum of sensible heat, latent heat, and snow heat fluxes is negative. This indicates that heat is transported from atmosphere to ground in winter. In summer, the situation is different; owing to the increase in downward solar radiation, one must be careful to determine whether surface net radiation is negative. Sensible heat fluxes were calculated from AWS profile measurements at three stations by HB88 (Holtslag et al., 1988), L79 (Louis, 1979) and G07 (Grachev et al., 2007) boundary layer parameterization schemes. The eddy covariance (EC) method was also used to calculate the sensible heat flux, using ultrasonic data at Zhongshan station. Details are given in Ma (2009). According to boundary layer theory, sensible heat flux is proportional to wind speed and inversely proportional to the temperature difference between atmosphere and ground. If air density and heat capacity are known, the slope of sensible flux scaled by wind speed versus temperature difference between air and ground is the sensible heat transfer coefficient $C_{\mathrm{H}}$. Figure 6 gives this relationship of observation and HIRHAM at three stations in summer. It is easy to distinguish features of HIRHAM: there is almost always a temperature inversion $\left(T_{2 \mathrm{~m}}-T_{\text {surf }}>0^{\circ} \mathrm{C}\right)$, and a negative sensible heat flux. This is significantly different from summer observations at the three stations, which do not always show temperature inversions and negative sensible heat fluxes. At Dome-A station (Figure 6(a)), inversion $\left(T_{2 \mathrm{~m}}-T_{\text {surf }}>0.5^{\circ} \mathrm{C}\right)$ cases represent $24 \%$ of all (1825) cases, and non-inversion $\left(T_{2 \mathrm{~m}}-T_{\text {surf }}<-0.5^{\circ} \mathrm{C}\right)$ cases $58 \%$. At Eagle station (Figure 6(b)), inversion cases comprise $36 \%$ of all (1790) cases, and non-inversion cases 31\%. At Zhongshan station (Figure 6(c)), inversion cases were $57 \%$ of the total (166), and non-inversion cases $8 \%$. This means that observed Antarctic near-surface (ground to $2 \mathrm{~m}$ ) temperature profiles showed both inversions and non-inversions, because there were both negative and positive sensible heat fluxes. Therefore, we discover one potential reason for the summer cold bias of HIRHAM versus observations; namely, the near-surface profile simulated by HIRHAM is almost always an inversion because heat is always transported from atmosphere to ground. The real boundary layer situation is 

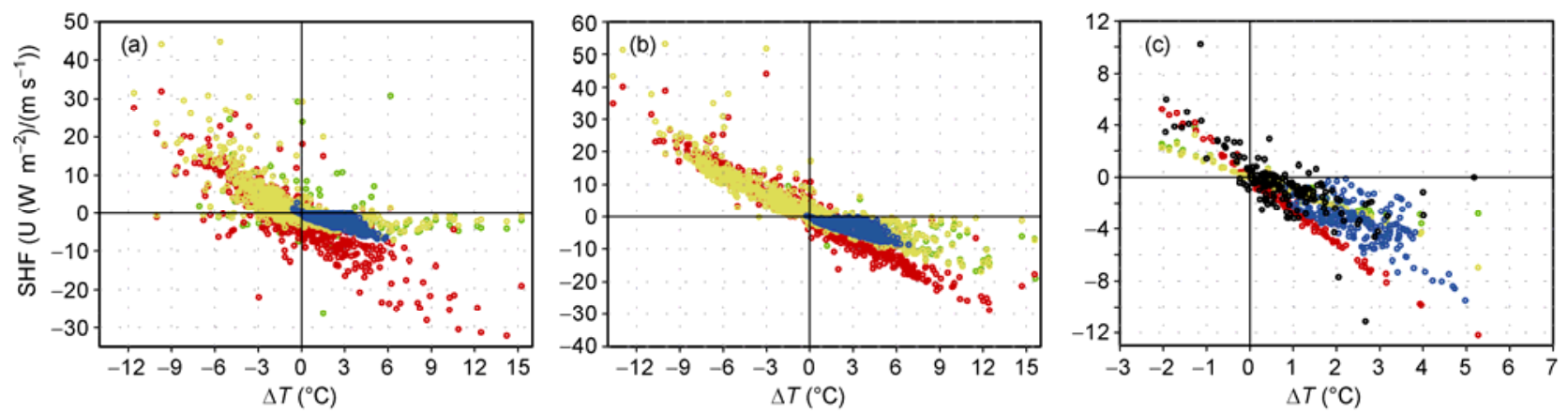

Figure 6 Scatter plot of wind-scaled sensible heat flux (SHF/U) with air-surface temperature difference from model (blue), EC observation (black), and observation-derived: green HB88 (Holtslag et al., 1988); red L79 (Louis, 1979); yellow G07 (Grachev et al., 2007). November, December, January, and February data during 2005-2008 at Dome-A (a) and Eagle (b); January and February data in 2008 at Zhongshan (c).
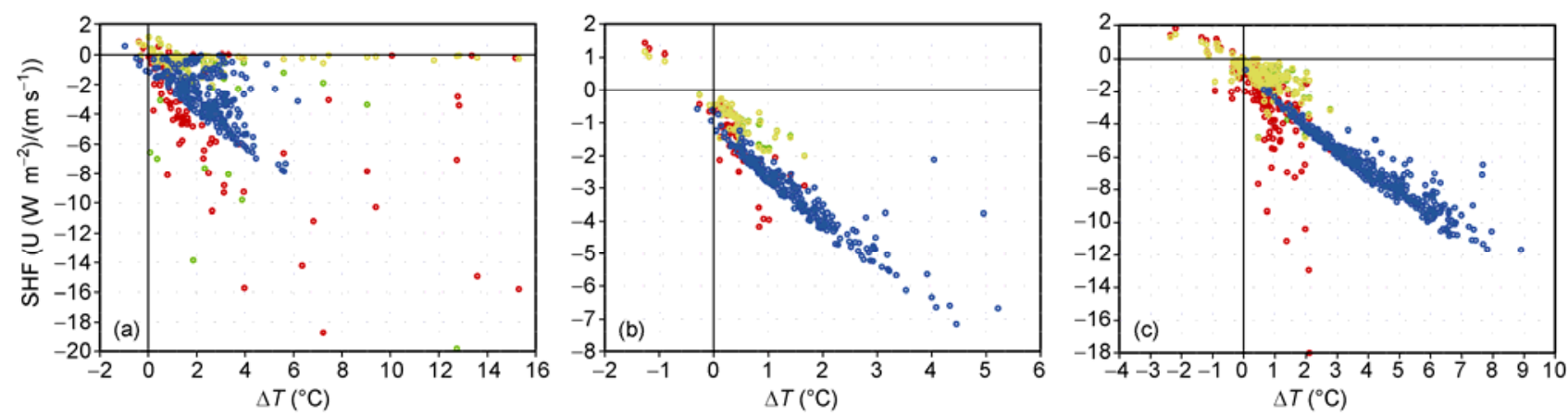

Figure 7 Similar to Figure 6, but for autumn and winter. April data from 2005 and 2008 at Dome-A (a) and Eagle (b); June, July, and August data from 2005 at Eagle (c).

different, so simulated 2-m temperature from HIRHAM is statistically colder than observation.

The AWS data have many missing and erroneous values in autumn and winter, but there are still some useful data; after they are quality controlled and plotted in Figure 7, they reveal a situation similar to Figure 6 . It is evident that the temperature profile and direction of sensible heat fluxes simulated by HIRHAM are nearly the same as the observations. This partially explains why the cold bias of HIRHAM in autumn and winter is not significant.

\section{Discussion and conclusions}

The Antarctic 2-m temperature field simulated by HIRHAM was averaged over 1958 to 1998, and then compared with ERA40 reanalysis, NCEP 20th-century reanalysis and station observations. The results show: (1) A cold bias of HIRHAM relative to reanalysis. The spatially averaged $2-\mathrm{m}$ temperature from HIRHAM is $1.8^{\circ} \mathrm{C}$ colder than ERA40 and $5.1^{\circ} \mathrm{C}$ colder than NCEP. (2) A seasonal difference in cold bias of HIRHAM relative to ERA40. In summer, the region-average cold bias is $3.4^{\circ} \mathrm{C}$; in autumn, the inland warm bias is $0.3^{\circ} \mathrm{C}$. Further study shows that the main reason for this is a difference in the summer boundary layer situation between HIRHAM and observations. (1) In sum- mer, both inversions and non-inversions are shown by observations, whereas there are almost always inversions in HIRHAM. (2) In autumn and winter, there are nearly always inversions in both HIRHAM and observations, which partially explains the small bias in these seasons.

In summary, the Antarctic summer boundary layer condition simulated by HIRHAM deviates from observation, which produces a 2-m temperature cold bias in the model. The main reason is that sensible heat fluxes simulated by HIRHAM are statistically different from observations. Because of complex atmospheric turbulence and interactions between air and ground within the boundary layer, the difference of sensible heat flux between HIRHAM and observation requires further study.

This research was supported by the Program of China Polar Environment Investigation and Assessment (2011-2015), the Basic Scientific Special Project "Climate System Model" of Chinese Academy of Meteorological Science (Grant No. 2012Z001) and the National Natural Science Foundation of China (Grant Nos. 41005045 and 41206179). The authors are thankful for AWS data collection from the members of the CHINAREN traverse route program, data preprocessing from $\mathrm{Dr}$. Ma and the manuscript comments from two reviewers.

Allison I, Morrissy J V. 1983. Automatic weather stations in the Antarctic. Aust Meteor Mag, 31: 71-76

Bailey D A, Lynch A H. 2000a. Development of an Antarctic regional 
climate system model. Part I: Sea ice and large-scale circulation. J Clim, 13: $1337-1350$

Bailey D A, Lynch A H. 2000b. Development of an Antarctic regional climate system model. Part II: Station validation and surface energy balance. J Clim, 13: 1351-1361

Bromwich D H, Monaghan A J, Manning K W, et al. 2005. Real-time forecasting for the Antarctic: An evaluation of the Antarctic Mesoscale Predition System (AMIPS). Mon Weather Rev, 133: 579-603

Chen B L, Zhang R H, Sun S F, et al. 2010a. A one-dimensional heat transfer model on Antarctic Ice Sheet and modeling of near-surface temperatures at Dome A, the summit of Antarctic Plateau. Sci China Earth Sci, 53: 763-772

Chen B L, Zhang R H, Xiao C D, et al. 2010b. Analysis on the air and snow temperatures near ground with observations of an AWS at Dome A, the summit of Antarctic Plateau. Chin Sci Bull, 55: 1430-1436

Christensen J H, Hewitson B, Busuioc A, et al. 2007. Regional climate projections. In: Solomon S, Qin D, Manning M, et al., eds. Climate Change 2007: The Physical Science Basis. Cambridge: Cambridge University Press. 847-940

Christensen J H, Christensen O B, Lopez P. 2006. The HIRHAM4 Regional Atmospheric Climate Model. Technical Report. DMI Sci Rep, 96-4, Dan Meteorol Inst, Copenhagen, Denmark

Connolley W M, Cattle H. 1994. The Antarctic climate of the UNKO unified model. Antarct Sci, 6: 115-122

Fouquart Y, Bonnel B. 1980. Computation of solar heating of the Earth's atmosphere: A new parameterization. Beitr Phys Atmos, 53: 35-62

Fraedrich K, Leslie L. 1991. Predictability studies of the Antarctic atmosphere. Aust Meteor Mag, 39: 1-9

Gao X J, Xu Y, Zhao Z C, et al. 2006. On the role of resolution and topography in the simulation of East Asia precipitation. Theor Appl Climatol, 86: $173-185$

Gao X J, Shi Y, Giorgi F. 2011. A high resolution simulation of climate change over China. Sci China Earth Sci, 53: 462-472

Giorgi F, Mearns L O. 1991. Approaches to regional climate change simulations: a review. Rev Geophys, 29: 191-216

Glushak K. 2008. Atmospheric circulation and the surface mass balance in a regional climate model of Antarctic. Doctoral Dissertation, Germany:
University of Potsdam. 143

Grachev A A, Andreas E L, Fairall C W, et al. 2007. SHEBA flux-profile relationships in the stable atmospheric boundary layer. Bound-Layer Meteor, 124: 315-333

Holtslag A A M, Bruin H A R. 1988. Applied modeling of the nighttime surface energy balance over land. J Appl Meteorol, 27: 689-704

Louis J F. 1979. A parameteric model of vertical eddy fluxes in the atmosphere. Bound-Layer Meteor, 17: 187-202

Ma Y F. 2009. Characteristic parameters of near surface layer of the traverse route from Zhongshan Station to Dome-A, East Antarctica (in Chinese). Master Thesis. Beijing: Chinese Academy of Meteorological Sciences

Meehl G A, Stocker T F, Collins W D, et al. 2007. Global climate projections. In: Solomon S, Qin D, Manning M, et al., eds. Climate Change 2007: The Physical Science Basis. Cambridge: Cambridge University Press. 747-846

Powers J G, Monaghan A J, Cayette A M, et al. 2003. Real-time mesoscale modeling over Antarctica: The Antarctic Mesoscale Prediction System (AMPS). Bull Amer Meteor Soc, 84: 1533-1545

Qu X, Hall A. 2005. Surface contribution to planetary albedo variability in cryosphere regions. J Clim, 18: 5239-5252

Reijmer C H, E van Meijgaard, van den Broeke M R. 2005. Evaluation of temperature and wind over Antarctica in a Regional Atmospheric Climate Model using 1 year of automatic weather station data and upper air observations. J Geophys Res, 110: D04103, doi: 10.1029/2004JD005234

Roeckner E, Bäuml G, Bonaventura L, et al. 2003. The Atmospheric General Circulation Model ECHAM5. Part 1. Model description. Technical Report. Report No.349, Max-Planck-Institut für Meteorologie (MPI-M)

Tiedtke M. 1989. A comprehensive mass flux scheme for cumulus parameterization in large-scale models. Mon Wea Rev, 117: 1779-1800

Undén P, Rontu L, Järvinen H, et al. 2002. HIRLAM-5 Scientific Documentation. Technical Report. European Meteorological Institutes

Wild M, Calanca P, Scherrer S C, et al. 2003. Effects of polar ice sheets on global sea level in high-resolution greenhouse scenarios. J Geophys Res, 108: $1-10$

Xin Y, Rinke A, Bian L, et al. 2010. Climate and forecast mode simulations for Antarctica: Implications for temperature and wind. Adv Atmos Sci, 27: 1453-1472 